\title{
Possible Connections between X-Solar Flares and Worldwide Variation in Seismicity Enhancement
}

\author{
Marilia Hagen" ${ }^{1}$ Anibal Azevedo² \\ ${ }^{1}$ Instituto de Fisica, Universidade Federal Fluminense, Niteroi, Brazil; ${ }^{2}$ Faculdade de Ciências Aplicadas da Unicamp, \\ Limeira, São Paulo
}

Correspondence to: Marilia Hagen, marhagen@indiana.edu; Anibal Azevedo, anibal.azevedo@fca.unicamp.br Keywords: Sun, Solar Wind, Coronal Mass Ejections, X-Flares, Earthquakes

Received: November 14, $2017 \quad$ Accepted: December 26, $2017 \quad$ Published: December 29, 2017

Copyright $\odot 2017$ by authors and Scientific Research Publishing Inc.

This work is licensed under the Creative Commons Attribution International License (CC BY 4.0).

http://creativecommons.org/licenses/by/4.0/

\section{(c) (i) Open Access}

\section{ABSTRACT}

We developed a statistical study analyzing global seismicity enhancement and its variation over twenty years. X-flares sometimes occur in conjunction with Coronal Mass Ejections (CME), which make their connection with the Earth's magnetosphere stronger. The preliminary study divided the Earth into seven regions determined by longitude and latitude, and nine levels of depth valid for most locations in the Pacific area. The results showed that $\mathrm{X}$ beams influenced seismicity in terrestrial localities, mainly high magnitude earthquakes occurring below the crust at $70 \mathrm{~km}$. These internal enhancements happen without the presence of any external forces such as studied in Solar Speed Winds. Nevertheless, those variations are perceptible in the presence of intense $\mathrm{X}$ flares and CME and less observed in the periods during which flares were absent. Two cases of high magnitude earthquakes in recent years are analyzed, and the extreme external conditions of those events fit with this theory.

\section{INTRODUCTION}

The complicated relationship between Solar activity and the Earth once more is considered in this research. Our previous papers, [1-3] described the gravitational forces between the system of three bodies, Sun, Moon, Earth, and how variation between the Sun and Earth was almost a constant due to the dimension of each body.

The interplanetary magnetic field is twice as strong as the Earth's magnetic field, and varies widely with the speed of the Solar wind. Variations in the Solar wind affect the Earth's magnetosphere and disturb the ionosphere. The question of whether these variations disturb the ground is still under discussion [4-6].

Solar flares produce high energy particles and radiation that are dangerous to live organisms. At the surface of the Earth, we are well protected from the effects of solar flares and other solar activity by the Earth's magnetic field and atmosphere [7]. The most dangerous emissions from flares are energetic 
charged particles (primarily high-energy protons) and electromagnetic radiation (mostly X-rays). The X-rays from flares are stopped by our atmosphere well above the Earth's surface. They do disrupt the Earth's ionosphere, which in turn disturbs some radio communications. Along with energetic ultraviolet radiation, they heat the Earth's outer atmosphere, causing it to expand. This radiation increases the drag on Earth-orbiting satellites, reducing their lifetime in orbit. All those external instabilities are well known; it is unknown if the X flares can disrupt the Earth's surface or if they are able to interfere with the Earth's internal magnetic field, thus enhancing hazard events. This research is a first step toward understanding if and how these effects would occur $[8,9]$.

Our last paper showed that there were no apparent connections between the crust, or inner earth, and solar activity for peak years in Solar Cycles 23 and 24, or the years 2000 and 2014 [3]. The behavior of events was entirely independent; they increased or decreased with no observed attachment to the Solar Cycles themselves $[10,11]$. At that time we found an enhancement of tremors in deeper depths for most of the three main worldwide areas studied. At first glance, these quakes appeared to be linked somehow to the electromagnetic waves energy created by coronal mass ejections and by the release of high energy particles during those events, especially if $\mathrm{X}$ flares also occurred $[12,13]$.

In order to arrive at a better understanding of this subject, we divided this paper into several sections: first, an explanation of coronal mass ejections, solar flares, and the possible interrelation between the earth's magnetosphere and the solar wind. Then, we provide a statistical study of X-flare occurrences across twenty years. We compare annual X-flare occurrences with the frequency of earthquakes spread worldwide. We divide the globe into seven regions defined by latitude and longitude, and each region is divided into nine depths that do not correspond to the usual layers considered by geologists. The objective of splitting regions into several layers of depth is to find out if earthquakes are interdependent not only by geographic area but also by depth. In this paper, we considered earthquakes $M>4.5$.

\section{SOLAR FLARES, CORONAL MASS EJECTIONS AND THEIR CONNECTIONS WITH EARTH.}

Coronal Mass Ejections (CME) and solar flares are energetic occurrences on the Sun. They are both associated with the Sun's magnetic fields. CMEs are large bubbles of magnetized gas which may take several hours to erupt into space. In this eruption, coronal material is expelled into space at high speeds, sometimes in the earth's direction. While CMEs are a huge eruption of the corona, flares can be considered relatively small or local events. Solar flares are giant explosions on the sun that send energy, light and high-speed particles into space. Solar flares are often associated with solar magnetic storms known as coronal mass ejections. Flares emit radiation in several bands of the electromagnetic spectrum (white light, ultraviolet, x-rays, gamma rays) and are observed by ground-based and space-based telescopes. Besides emitting radiation, solar flares also accelerate particles which are ejected into space. Solar flares are classified according to $\mathrm{x}$-ray intensity. They are classified by letters and numbers; the most important of these classifications are the $\mathrm{M}$ and $\mathrm{X}$ flares, the last one being the strongest. X-ray flares are measured in Watts per meters squared. The numerical values are, $\mathrm{M}=1.0 \times 10^{-5}\left(\mathrm{~W} \cdot \mathrm{m}^{-2}\right)$ and, $\mathrm{X}=1.0 \times 10^{-4}\left(\mathrm{~W} \cdot \mathrm{m}^{-2}\right)$. For example, the intensity of a flare M2.3 will be $2.3 \times 10^{-5} \mathrm{~W} \cdot \mathrm{m}^{-2}[12,13]$. When a CME erupts from the Sun, the ejected coronal material moves through the solar wind and creates a disturbance. This disturbance may include a shock wave that moves ahead of the CME, accelerating some solar wind particles to high energies as it moves. This process adds to any other energetic particles that may be present from an associated flare. If the CME reaches the Earth, there can be significant consequences to communications, satellite operations and power generation. The speed at which a CME leaves the Sun can vary, but typically the majority of the material reaches earth in 3 to 4 days. Both events may often occur together or singly. Solar flares are energetic explosions in the low solar atmosphere which can heat the surrounding material to millions of degrees in just a few seconds or minutes $[14,15]$. Our observations took data from twenty years of observed X flares. In this paper, we are only considering the presence of X-flares, as the disturbances created by $\mathrm{M}$-flares are small by comparison and do not disturb the magnetosphere as X-flares. In the next part of this paper, we calculated average X-flare data for each year and compared those figures to the number of 
earthquakes in each year to determine whether earthquake activity increased or not.

Figure 1 was created using the method described in Section 3. It shows that 2011 had an anomalous high occurrence of $\mathrm{X}$ flares and an average number of earthquakes. We did not include years with zero $\mathrm{X}$-flares in our calculations. The calculations that possibly link earthquakes and solar flares are modeled on the following $[16,17]$. First, we counted the number of earthquakes M4.5 for four days following the day the X-solar flare was released by the Sun, and compared this figure to the total number of earthquakes that happened each month. After one year we have the number of earthquakes that occurred during the Solar flares above or below the total events. We followed the same procedure for twenty years and obtained the plot above. Although the number of earthquakes varies during years with more $\mathrm{X}$ flares, it is not a consistent change. Some world regions have more events than others. Therefore, it was necessary to divide those regions with tremors by magnitude and depth.

\section{EARTH REGIONS AND DEPTHS}

The next sections will show the results obtained for six different regions around the world, divided by the coordinates. In certain areas, those regions overlap since it is a global map. Therefore, we must correct possible mistakes by hand. The regions are East Pacific (area A), Asia (West Pacific), Europe, Africa (area B), South Atlantic Ocean, South America (area C), Canada, North America, Mexico, Central America (area D), Europe, North Africa, North Atlantic, Caribbean (area E), Arctic sea, Greenland, North Atlantic, (area F), South Atlantic, South Pacific, South Indian Ocean, Southern Ocean (area G), as in the Table 1.

Depth of activity is also diverse depending on the locations studied; we decided to divide into between one and nine depths depending on the region analyzed. The areas West Pacific, East Pacific, Europe, Africa, South Atlantic Ocean, South America have nine depths. Canada, North America, North Atlantic, Mexico, Central America comprise five depths. South Atlantic, South Pacific, South Indian Ocean and the Southern Ocean, Europe, North Africa, North Atlantic, and the Caribbean include four depths. Arctic Sea, Greenland and North Atlantic are limited to one depth. See Table 2.

Observation of Table 2 indicates some parts of the earth's surface that are more dynamic than others in magnitude and range of depths. The most intriguing is the area in South America where we found one depth layer was inactive, but below that the region was active again. Establishment of region and depth categories makes it more accessible to search how seismicity changes by location. In the next section, we characterize locations and depths to understand their behavior. Working with high numbers of data, we must develop tools to oversee calculations so that we do not find unrealistic results.

\section{Flares vs enhancement of quakes}

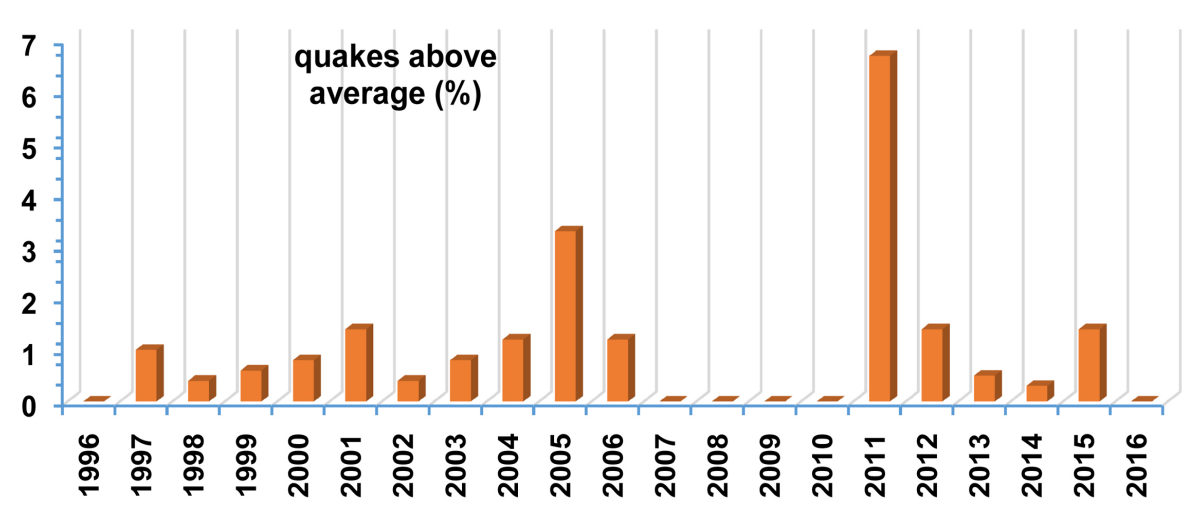

Figure 1. X flares and the enhancement of seismic events above M4.5. within four days of each X-flare event, compared to the monthly average. 
Table 1. The coordinates of 7 worldwide areas. Areas F and G are near poles.

\begin{tabular}{cc}
\hline Areas & Coordinates \\
\hline W. Pacific (AMERICAS): area A & $70.14 \mathrm{~N},-54.16 \mathrm{~S},-65.04 \mathrm{E},-139.57 \mathrm{~W}$ \\
E. Pacific (Asia), Europe, Africa: area B & $79.56 \mathrm{~N},-30.75 \mathrm{~S}, 136.05 \mathrm{E},-18.03 \mathrm{~W}$ \\
South Atlantic Ocean, South America: area C & $10.83 \mathrm{~N},-69.78 \mathrm{~S}, 17.75 \mathrm{E},-71.89 \mathrm{~W}$ \\
Canada, N. America, N. Atlantic, Mexico, Central & $71.52 \mathrm{~N}, 1.76 \mathrm{~S},-20.12 \mathrm{E},-160.06 \mathrm{~W}$ \\
America: area D & $73.23 \mathrm{~N}, 2.81 \mathrm{~S}, 43.42 \mathrm{E},-81.04 \mathrm{~W}$ \\
Europe, N. Africa, N. Atlantic: area E & $83.91 \mathrm{~N},-64.47 \mathrm{~S}, 7.38 \mathrm{E},-39.02 \mathrm{~W}$ \\
Arctic Sea, Greenland, Atlantic: area F & \\
South Atlantic, South Pacific, South Indian Ocean, & $(-) 35.689 \mathrm{~N},-82.118 \mathrm{~S}, 36.56 \mathrm{E},-167,344 \mathrm{~W}$ \\
Southern Ocean: area G &
\end{tabular}

\section{METHOD TO CALCULATE THE X-FLARES AND EARTHQUAKES VARIATIONS}

The method used to distinguish the earthquakes in different areas and depths are described in [3]. Now, we separated the world into regions A-G defined above (seven locations). We examined activity by depth in those areas, and defined depths range from levels $1-9$. We tracked operation during a period of twenty years, 1996-2016, for a total of 20 years calculations.

We recorded all earthquakes for each year according to the depth and divided them by level. For the shallower stages, we considered magnitudes $\mathrm{M} \geq 4.5$. Therefore, we constructed a table of $\mathrm{N}$ values for each year. When these values are added, and the total is divided by 20 , we are left with the average number of events per year. Then, each year is divided by the average; the result shows how many times the number of earthquakes in each year was below, above, or on the average.

\subsection{Construction of Plots and Tables}

The dataset comprises earthquakes recorded during the period 1996-2016. The sum of data values was $\mathrm{y}_{1}=$ data recorded in the first-year level $\mathrm{n}(0-35 \mathrm{~km}, \geq 500 \mathrm{~km})$ in the region $\mathrm{X}(\mathrm{A}, \mathrm{B}, \mathrm{C}, \mathrm{D}, \mathrm{E}, \mathrm{F}, \mathrm{G})$

$$
\sum_{n 0}^{n n} Y_{n}=y_{n 0}+y_{n 1}+\cdots+y_{n n^{\prime}}
$$

where $n=1996, \cdots, 2016$, and $n$ 'is 20 years.

The mean is defined as

$$
\text { Mean }=A=\frac{\sum_{n 0}^{n n} Y_{n}}{20}
$$

Each year earthquake occurrences are divided by the average $A$.

$\frac{Y_{n 0}}{A}=Y_{n 0}^{\prime}$-the new number $Y_{n 0}^{\prime}$ will be the relation between the average number of earthquakes for the requested year. The variation is always expressed as a positive number in relation to the average. However, it also can be zero. This method was also applied to find X-flare variation during the same period. We applied the same calculation for the number of depths recorded active for each location, as described in Section 2. The next sections explain each region and discuss the earthquakes that occurred. We also compared the enhancement of earthquakes in the years with $\mathrm{X}$ flares $>1, \mathrm{X}<1$ and $\mathrm{X}=0$ for each region and depth studied. The following Tables were created following those calculations. 
Table 2. The depths considered for each region analyzed for earthquakes. Observe the third area has no events recorded between 300 and $500 \mathrm{~km}$, but includes tremors below that level.

\section{Depths recorded}

West Pacific, East Pacific, Europe, Africa-A, B, C

Depth 0 - $35 \mathrm{~km}$ : upper crust

Depth 35 - 70 km: lower crust

Depth 70 - 100 km: lower crust

Depth 100 - 200 km: lithosphere

Depth 200 - $300 \mathrm{~km}$ : asthenosphere

Depth 300 - 400 km

Depth 400 - 500 km

Depth 500 - 600 km

Depth $600-800 \mathrm{~km}$

South Atlantic Ocean, South America-D

Depth 0 - $35 \mathrm{~km}$ : upper crust

Depth 35 - 70 km: lower crust

Depth 70 - $100 \mathrm{~km}$ : lower crust

Depth 100 - 200 km: lithosphere

Depth 200 - $300 \mathrm{~km}$ : asthenosphere

Depth 500 - 600 km

Depth $600-800$ km

Europe, North Africa, North Atlantic, and Caribbean-E

Depth 0 - $35 \mathrm{~km}$ : upper crust

Depth 35 - 70 km: lower crust

Depth 70 - $300 \mathrm{~km}$

Depth 300 - 500 km

Arctic Sea, Greenland and North Atlantic-F

0 - $35 \mathrm{~km}$ :crust

South Atlantic, South Pacific, South Indian Ocean and Southern Ocean-G

Depth 0 - $35 \mathrm{~km}$ : upper crust

Depth 35 - 70 km: lower crust

Depth 70 - 300 km 
Table 3. This table show the East Pacific area variation in the average number of earthquakes over the last twenty years. There are nine depths for each year result.

\begin{tabular}{|c|c|c|c|c|c|c|c|c|c|}
\hline & & & East & Pacific & & & & & \\
\hline Year & $\begin{array}{c}0-35 \\
\mathrm{~km}\end{array}$ & $\begin{array}{c}35-70 \\
\mathrm{~km}\end{array}$ & $\begin{array}{c}70-100 \\
\mathrm{~km}\end{array}$ & $\begin{array}{c}100-200 \\
\mathrm{~km}\end{array}$ & $\begin{array}{c}200-300 \\
\mathrm{~km}\end{array}$ & $\begin{array}{c}300-400 \\
\mathrm{~km}\end{array}$ & $\begin{array}{c}400-500 \\
\mathrm{~km}\end{array}$ & $\begin{array}{c}500-600 \\
\mathrm{~km}\end{array}$ & $\begin{array}{c}>600 \\
\mathrm{~km}\end{array}$ \\
\hline 1996 & 0.9 & 0.3 & 0.8 & 0.8 & 0.8 & 1 & 1.2 & 1.2 & 0.6 \\
\hline 1997 & 0.7 & 0.3 & 1 & 1.1 & 1.1 & 1.2 & 1.3 & 1.1 & 0.8 \\
\hline 1998 & 0.5 & 0.4 & 0.9 & 0.9 & 1.1 & 0.7 & 0.9 & 0.8 & 0.8 \\
\hline 1999 & 0.6 & 0.3 & 0.8 & 0.8 & 0.8 & 0.6 & 0.7 & 0.6 & 1 \\
\hline 2000 & 0.9 & 0.4 & 0.7 & 0.8 & 0.8 & 0.7 & 0.7 & 0.6 & 1.3 \\
\hline 2001 & 0.8 & 0.4 & 0.8 & 0.7 & 0.8 & 1 & 0.7 & 0.7 & 0.5 \\
\hline 2002 & 0.7 & 0.5 & 0.9 & 0.9 & 1 & 1.1 & 1.2 & 1.2 & 1.7 \\
\hline 2003 & 0.8 & 0.5 & 1.1 & 0.9 & 0.9 & 1.4 & 1.1 & 1 & 0.5 \\
\hline 2004 & 0.7 & 0.3 & 1.1 & 1.1 & 0.9 & 0.7 & 1 & 1 & 1.6 \\
\hline 2005 & 0.6 & 1.1 & 1.1 & 1 & 1 & 1 & 1 & 1.1 & 0.6 \\
\hline 2006 & 0.9 & 1.4 & 1.2 & 1.2 & 1 & 1.1 & 1.3 & 1.3 & 1 \\
\hline 2007 & 1.2 & 1.4 & 1.1 & 1.2 & 1.1 & 1 & 1.3 & 1 & 1 \\
\hline 2008 & 0.9 & 1.4 & 1.1 & 1 & 1 & 1.8 & 1.1 & 1 & 1 \\
\hline 2009 & 1.1 & 1.2 & 1 & 0.9 & 0.8 & 0.9 & 0.7 & 0.5 & 1 \\
\hline 2010 & 1.4 & 1.6 & 0.9 & 1 & 1 & 0.9 & 0.7 & 0.8 & 1.2 \\
\hline 2011 & 1.6 & 2.2 & 1.4 & 1 & 1.3 & 1.1 & 0.9 & 0.7 & 0.9 \\
\hline 2012 & 0.8 & 1.3 & 1.3 & 1.1 & 1.1 & 1 & 0.9 & 0.8 & 0.7 \\
\hline 2013 & 0.9 & 1.1 & 1.2 & 1.1 & 1.1 & 1 & 0.9 & 1.1 & 1 \\
\hline 2014 & 0.9 & 1.5 & 1.2 & 1.3 & 1.2 & 1.1 & 1.4 & 1.6 & 1.5 \\
\hline 2015 & 0.9 & 1.3 & 1.1 & 1.2 & 1.2 & 1 & 0.9 & 1.3 & 1 \\
\hline 2016 & 2.3 & 0.2 & 1.2 & 1.2 & 1.1 & 1.1 & 0.9 & 1.6 & 1 \\
\hline
\end{tabular}

In Table 3, the most active depths were below $500 \mathrm{~km}-600 \mathrm{~km}$ which had ten maxima in the twenty years, followed by $400-500 \mathrm{~km}$ and $200-300 \mathrm{~km}$ with eight maxima. For the shallower levels, we found $37-100 \mathrm{~km}$ with nine peaks. In the East Pacific, we found a variation below the crust and the most significant changes are in the lowest depths of $500 \mathrm{~km}-600 \mathrm{~km}$ with no connection to any external movements or fluctuations. This supports the idea that at this depth there is brittle material and low elasticity. The tables with deepest events showed the highest number of variations in the tremors during several consecutive years, without relating to the shallower depths. This means that those enhancements were completely independent of the other increases.

In the area displayed in Table 4, the earthquake enhancement was highest at the depth $35-70 \mathrm{~km}$ from 2004-2014, and $200-500 \mathrm{~km}$ at other times. In this region, Africa did not present any earthquake below $40 \mathrm{~km}$. The deepest event time and location was in Malawi, M4.8 at $46.4 \mathrm{~km}$ in 1998 . The continent looks to offer a rigidity that is higher than other regions examined. Observe the deepest events between $600-700 \mathrm{~km}$ when the enhancement of quakes reached two times the average and sometimes almost four times the average. This location has the deepest depth events around the Mediterranean Sea. All of the 
Table 4. A variation of average earthquakes in the area Asia (West Pacific), Europe, and Asia.

\begin{tabular}{cccccccccc}
\hline \multicolumn{7}{c}{ West Pacific (Asia), Europe, Africa } & & & \\
\hline Year & $0-35$ & $35-70$ & $70-100$ & $100-200$ & $200-300$ & $300-400$ & $400-500$ & $500-600$ & $>600 \mathrm{~km}$ \\
& $\mathrm{~km}$ & $\mathrm{~km}$ & $\mathrm{~km}$ & $\mathrm{~km}$ & $\mathrm{~km}$ & $\mathrm{~km}$ & $\mathrm{~km}$ & $\mathrm{~km}$ & \\
\hline 1996 & 0.9 & 0.3 & 0.8 & 0.9 & 1 & 1.5 & 1.3 & 1.4 & 2 \\
1997 & 0.6 & 0.3 & 1 & 1.1 & 1.3 & 1 & 1.5 & 1.4 & 1.3 \\
1998 & 0.5 & 0.3 & 1 & 0.9 & 1 & 0.8 & 1.4 & 1 & 0.9 \\
1999 & 0.7 & 0.4 & 0.8 & 0.9 & 0.9 & 0.7 & 0.7 & 0.7 & 0.7 \\
2000 & 0.8 & 0.4 & 0.9 & 0.8 & 0.8 & 0.5 & 0.7 & 0.6 & 1.1 \\
2001 & 0.8 & 0.3 & 0.7 & 0.7 & 0.8 & 0.8 & 0.6 & 0.8 & 0.7 \\
2002 & 0.8 & 0.4 & 0.7 & 0.8 & 0.9 & 1 & 1.4 & 1 & 0.7 \\
2003 & 0.8 & 0.3 & 0.9 & 1 & 0.8 & 1.5 & 1.1 & 1.1 & 2 \\
2004 & 1 & 1.2 & 1.4 & 1.1 & 1.2 & 0.6 & 1 & 1.4 & 0.6 \\
2005 & 1.7 & 1.4 & 0.8 & 0.9 & 1 & 1.3 & 1.1 & 1 & 0.7 \\
2006 & 1.1 & 1.6 & 0.8 & 1 & 1 & 1.7 & 1.3 & 1.5 & 0.7 \\
2007 & 1.2 & 2 & 1.2 & 1.2 & 1.5 & 0.7 & 1 & 0.7 & 0 \\
2008 & 1.2 & 2.5 & 1.2 & 1.3 & 1.3 & 1.8 & 1.4 & 1.3 & 0.4 \\
2009 & 1.2 & 1.7 & 1.1 & 0.9 & 0.5 & 0.9 & 0.7 & 1 & 1.3 \\
2010 & 0.2 & 1.3 & 1 & 1.2 & 0.8 & 1 & 0.6 & 1.5 & 3.6 \\
2011 & 0.7 & 1.2 & 1.3 & 1.1 & 1.2 & 1.3 & 1 & 0.9 & 1 \\
2012 & 1 & 1.5 & 1.2 & 1.2 & 0.8 & 0.9 & 1.3 & 0.5 & 1 \\
2013 & 0.7 & 1.1 & 1 & 1 & 1.4 & 1.1 & 0.9 & 0.9 & 0.4 \\
2014 & 0.9 & 1.6 & 1.3 & 1 & 1.1 & 0.8 & 0.7 & 0.9 & 0.3 \\
2015 & 0.7 & 1.1 & 0.8 & 1 & 1.3 & 1.3 & 0.7 & 0.9 & 0.4 \\
2016 & 3 & 0.4 & 1 & 9 & 1 & 0.9 & 0.6 & 0.8 & 0.3 \\
\hline
\end{tabular}

deepest tremors occur near the shoreline of Italy.

The earthquake enhancement for this region (Table 5) was concentrated at depths of $70-200 \mathrm{~km}$. Depths $300-500 \mathrm{~km}$ were inactive, with no event recorded in twenty years. The depths $500-700 \mathrm{~km}$ presented a variation as the Table shows. At an intraplate location in South America, extending along the coasts of Brazil to Argentina, there are no earthquakes atadepth of $200 \mathrm{~km}-500 \mathrm{~km}$. There is a buried region in South America that borders several countries, Brazil, Bolivia and Argentina, where there are no tremors in the range $200 \mathrm{~km}-500 \mathrm{~km}$. Below $500 \mathrm{~km}$ the same region is seismically active again. It suggest the presence of brittle material at $500 \mathrm{~km}$ and below. We will make another study focusing on this region to support this idea.

In Table 6, the activity is concentrated at depths of $35-100 \mathrm{~km}$. There are no events below $300 \mathrm{~km}$. However an anomalous enhancement occurred in 1997 in the $200-300 \mathrm{~km}$ range. The deepest earthquakes are all localized in Central America on the East side of the Pacific in a similar path to the one observed in South America's deepest tremors. It is remarkable they are at the same depth, $200-300 \mathrm{~km}$, although in Central America there are no occurrences below this depth. In this location, the deepest level presented enhancement anomalies below $200 \mathrm{~km}$ over several years. 
Table 5. South Atlantic Ocean, South America. This region presents an anomaly in the data, the depth $200-500 \mathrm{~km}$ is inactive. Only three earthquakes happened: two in Chuquisada and one in Cochabamba, both of which are in Bolivia.

\begin{tabular}{cccccccc}
\hline \multicolumn{7}{c}{ South Atlantic Ocean, South America } \\
\hline Year & $0-35 \mathrm{~km}$ & $35-70 \mathrm{~km}$ & $70-100 \mathrm{~km}$ & $100-200 \mathrm{~km}$ & $200-300 \mathrm{~km}$ & $500-600 \mathrm{~km}$ & $>600 \mathrm{~km}$ \\
\hline 1996 & 0.4 & 0.5 & 0.7 & 0.5 & 0.6 & 0 & 0 \\
1997 & 0.5 & 0.6 & 0.9 & 0.9 & 1.3 & 0.5 & 2 \\
1998 & 0.4 & 1.5 & 0.9 & 0.8 & 1 & 1 & 0.5 \\
1999 & 0.4 & 0.9 & 0.5 & 0.5 & 0.6 & 0.5 & 0 \\
2000 & 0.5 & 0.7 & 0.2 & 0.6 & 1.1 & 0.3 & 1.5 \\
2001 & 0.5 & 1.1 & 0.5 & 0.6 & 1 & 0 & 0 \\
2002 & 0.6 & 1.7 & 0.8 & 0.8 & 1 & 0.9 & 1 \\
2003 & 0.6 & 2 & 0.6 & 0.6 & 0.5 & 1.5 & 0.5 \\
2004 & 0.9 & 1.5 & 1.2 & 0.8 & 0.7 & 1 & 0 \\
2005 & 0.8 & 1.3 & 1 & 1.1 & 1 & 1.6 & 1.5 \\
2006 & 1 & 2.1 & 1.1 & 1.2 & 1.3 & 0.9 & 0 \\
2007 & 1 & 1.8 & 0.5 & 1.3 & 1.2 & 0.9 & 0.5 \\
2008 & 0.8 & 0.9 & 1.2 & 0.9 & 1.1 & 0.9 & 0 \\
2009 & 0.9 & 0.3 & 0.9 & 0.9 & 1.1 & 0.5 & 2 \\
2010 & 0.9 & 0.9 & 0.9 & 1 & 1 & 1.3 & 1 \\
2011 & 0.8 & 0.4 & 1.6 & 1.2 & 0.7 & 2.5 & 0 \\
2012 & 1 & 0.4 & 1.5 & 1.1 & 1.3 & 1.5 & 0.5 \\
2013 & 2 & 0.4 & 1.5 & 1.4 & 1 & 0.9 & 0.5 \\
2014 & 3 & 0.6 & 1.5 & 1.4 & 1.3 & 1 & 1 \\
2015 & 1.9 & 1.1 & 0.4 & 1.3 & 1.2 & 0.9 & 4 \\
2016 & 2.5 & 0.6 & 1.7 & 1.2 & 1.6 & 1.8 & 0.5 \\
\hline
\end{tabular}

Table 7 indicates that disturbances in this location occur most frequently in shallower depths of 0 - 35 $\mathrm{km}$. Only a few points have disturbances at $35-70 \mathrm{~km}$. The disturbances at depths of $70-299 \mathrm{~km}$ are substantially connected with just a few spots in the Caribbean region and the Mediterranean Sea. The deepest earthquakes happened all over the Mediterranean and the Italian shoreline. These disturbances appear to be associated with profound internal variations of the Earth. Table 6 and Table 7 show the strongest anomalies in the enhancement of quakes at depths of $300-500 \mathrm{~km}$. As both Tables indicate, sometimes the increase of events was over 3 times the average, as in 1996. Other years, including 2000 and 2001 also showed an enhancement in the deepest depths at higher rates than at any other level. This enhancement is concentrated in small areas as in the Mediterranean sea and indicates internal ruptures during that time and location.

Events in this region with depth $>300 \mathrm{~km}$ are all located in the Scotia Sea (Table 8). Notable enhancements occurred during the last two years studied, 2015 and 2016. A depth that was affected more is $70-300 \mathrm{~km}$, showing enhancement during nine nearly consecutive years after 2004. Finally, the last region 
Table 6. This region includes events at fewer depth ranges; the lowest activity level is $300 \mathrm{~km}$ rather than up to $700 \mathrm{~km}$ in depth as in other regions. Canada, North America, Mexico and, Central America.

\begin{tabular}{|c|c|c|c|c|c|}
\hline \multicolumn{6}{|c|}{ Canada, North America, Mexico, Central America } \\
\hline Year & $0-35 \mathrm{~km}$ & $35-70 \mathrm{~km}$ & $70-100 \mathrm{k}$ & $100-200 \mathrm{~km}$ & $200-300 \mathrm{~km}$ \\
\hline 1996 & 0.9 & 0.4 & 0.8 & 0.5 & 0.3 \\
\hline 1997 & 0.9 & 0.4 & 1 & 1 & 2.3 \\
\hline 1998 & 0.7 & 0.7 & 0.7 & 0.7 & 0.3 \\
\hline 1999 & 0.7 & 0.6 & 0.5 & 0.5 & 1.3 \\
\hline 2000 & 0.8 & 0.7 & 0.8 & 0.8 & 0.3 \\
\hline 2001 & 1 & 0.7 & 0.9 & 0.9 & 0.3 \\
\hline 2002 & 1 & 0.7 & 1 & 1 & 1 \\
\hline 2003 & 0.9 & 0.5 & 0.9 & 0.9 & 1 \\
\hline 2004 & 1.1 & 0.8 & 0.8 & 0.8 & 1.3 \\
\hline 2005 & 0.7 & 0.7 & 1 & 1 & 0.3 \\
\hline 2006 & 1 & 1.1 & 0.9 & 0.9 & 0.7 \\
\hline 2007 & 1.4 & 1.3 & 1.4 & 1.4 & 0.3 \\
\hline 2008 & 1.3 & 1.5 & 1.2 & 1.2 & 1 \\
\hline 2009 & 1.2 & 1 & 1.2 & 1.2 & 0.7 \\
\hline 2010 & 1.3 & 0.8 & 1.5 & 1.5 & 2.7 \\
\hline 2011 & 1 & 1.1 & 1.3 & 1.3 & 0.7 \\
\hline 2012 & 1.3 & 1.4 & 0.9 & 0.9 & 2 \\
\hline 2013 & 0.8 & 1.5 & 1 & 1 & 0.7 \\
\hline 2014 & 1 & 2 & 1.3 & 1.3 & 1 \\
\hline 2015 & 0.8 & 1.9 & 1.3 & 1.3 & 0.7 \\
\hline 2016 & 4 & 0.1 & 1.2 & 1.2 & 1 \\
\hline
\end{tabular}

considered is at higher latitudes, such as the Arctic Sea, Greenland, and North Atlantic. The only variation in this location is in the shallowest range of $0-35 \mathrm{~km}$. Only four years showed some enhancement, in $2005,2008,2014$, and 2015. The locations of the deepest earthquakes were in Iceland. However, there were no events below $20 \mathrm{~km}$. This means either that the region is not brittle below this depth or the material is more malleable than the strata above. There are locations with quakes in the depth of $600-800 \mathrm{~km}$ suggesting the level is brittle and not melted as geologists commonly believe today.

In the first part of this research, we talked about the solar flares and how they varied over twenty years. Figure one shows the frequency of solar flares in relation to variations in average earthquakes for each year. However, measuring the total number of earthquakes does not distinguish between events by 
Table 7. The deepest tremors are at $400-500 \mathrm{~km}$, localized in a few points around the Mediterranean Sea. Europe, North Africa, North Atlantic and, Caribbean.

\begin{tabular}{|c|c|c|c|c|}
\hline & Europe & N. Africa & N. Atlantic & Caribbean \\
\hline Year & $0-35 \mathrm{~km}$ & $35-70 \mathrm{~km}$ & $70-300 \mathrm{~km}$ & $300-500 \mathrm{~km}$ \\
\hline 1996 & 0.9 & 0.1 & 0.4 & 3 \\
\hline 1997 & 1 & 0.1 & 0.4 & 1 \\
\hline 1998 & 0.8 & 0.4 & 0.7 & 2 \\
\hline 1999 & 0.8 & 0.4 & 0.6 & 0.5 \\
\hline 2000 & 0.7 & 0.5 & 0.7 & 1.5 \\
\hline 2001 & 0.7 & 0.5 & 0.6 & 3 \\
\hline 2002 & 0.8 & 0.6 & 0.6 & 1.5 \\
\hline 2003 & 1 & 0.5 & 0.6 & 1 \\
\hline 2004 & 1 & 0.9 & 0.8 & 1 \\
\hline 2005 & 1 & 1 & 1 & 0.5 \\
\hline 2006 & 0.8 & 2 & 2 & 2 \\
\hline 2007 & 1.4 & 2 & 2 & 2.5 \\
\hline 2008 & 1 & 2 & 2 & 1.5 \\
\hline 2009 & 0.9 & 1 & 1 & 0 \\
\hline 2010 & 1 & 0.5 & 0.5 & 0.5 \\
\hline 2011 & 1 & 0.8 & 1 & 0.5 \\
\hline 2012 & 0.8 & 1.5 & 1 & 0.5 \\
\hline 2013 & 0.8 & 1.3 & 1 & 0.5 \\
\hline 2014 & 1.7 & 2 & 1.5 & 0.5 \\
\hline 2015 & 0.7 & 2 & 2 & 1 \\
\hline 2016 & 1 & 0.2 & 0.5 & 0.5 \\
\hline
\end{tabular}

depth or region. Next, we need to examine how solar flares affected earthquakes according to depth, and also account for earthquakes that did not occur within four days of an X-flare. We start with two specific earthquakes that fit the requirements of this paper.

\subsection{Analyse of Two Large Earthquakes}

\subsubsection{Japan Earthquake (2011)}

On 11 March 2011, an earthquake that measured 8.9 on the Richter scale affected Japan. This earthquake occurred after several years without X flare events. The first X-flare in 2011 was in February, and the next occurrence was an X1.5 class explosion on 9 March. This flare was associated with CMEs toward Earth; and occurred after five years of a quiet Sun. The earthquake in Japan had more than 800 aftershocks 
Table 8. There are few events at the greatest depths. Most variations occurred in the $70-300 \mathrm{~km}$ range. The region includes the most southern locations worldwide in the South Atlantic, South $\mathrm{Pa}$ cific, Indian Ocean, and Southern Ocean.

\begin{tabular}{|c|c|c|c|c|}
\hline \multicolumn{5}{|c|}{ S. Atlantic Ocean, S. Pacific, S. Indian Ocean, Southern Ocean } \\
\hline Year & $0-35 \mathrm{~km}$ & $35-70 \mathrm{~km}$ & $70-300 \mathrm{~km}$ & $300-500 \mathrm{~km}$ \\
\hline 1996 & 0.4 & 0 & 0.5 & 0 \\
\hline 1997 & 0.6 & 0 & 0.5 & 0 \\
\hline 1998 & 0.5 & 0 & 0.5 & 0 \\
\hline 1999 & 0.5 & 0 & 0.5 & 1 \\
\hline 2000 & 0.6 & 0 & 0 & 0 \\
\hline 2001 & 0.7 & 0 & 0 & 0 \\
\hline 2002 & 0.8 & 0 & 0.8 & 0 \\
\hline 2003 & 0.6 & 0 & 0.6 & 0 \\
\hline 2004 & 0.7 & 0 & 1.3 & 1 \\
\hline 2005 & 0.7 & 0 & 1 & 1 \\
\hline 2006 & 0.7 & 0.7 & 1.3 & 0 \\
\hline 2007 & 0.8 & 1 & 1.3 & 0 \\
\hline 2008 & 1 & 1.2 & 0.9 & 0 \\
\hline 2009 & 1 & 1 & 0.9 & 1 \\
\hline 2010 & 3 & 8.2 & 1 & 1 \\
\hline 2011 & 1 & 1.3 & 2 & 0 \\
\hline 2012 & 1 & 1 & 1.7 & 0 \\
\hline 2013 & 1.7 & 1.5 & 1.7 & 0 \\
\hline 2014 & 1.6 & 1 & 1.6 & 0 \\
\hline 2015 & 1.5 & 1.3 & 1.4 & 2 \\
\hline 2016 & 1.9 & 1 & 1.4 & 2 \\
\hline
\end{tabular}

ranging from depths of $26 \mathrm{~km}$ to below $100 \mathrm{~km}$. It took five days for all the quakes $\mathrm{M}>4.0$ to stop. Our previous studies pointed out amega earthquake is caused by a conjugation of external factors. It was also the New Moon changing to the first quarter, when the moon is facing the Sun changing to $1^{\text {st }}$ Quarter. The second coincidence was the X flares coupled to the CMEs happening after five years absence. The last requirement was to be at the subduction zone. These factors converged in this quake.

\subsubsection{Mexico Earthquake (2017)}

An Earthquake of magnitude 8.1 struck off the coast of Chiapas, Mexico on 8 September 2017. It was during the Full moon, which started on 6 September, and followed the strongest X flares on September 4 
with magnitude X9.3. These flares were also associated with CMEs larger than those observed in 2011. This earthquake also happened in a subduction zone. Unfortunately, the monitoring and recording of $\mathrm{X}$ flares by NASA (reference) started in 1996 and before this time we have no means to track a possible long-term connection between flares and earthquakes. There was a swarm of earthquakes, however. They were much deeper than in Japan, although focused in a smaller area. However, in these two events the conditions were similar, combining gravitational forces from the moon, $\mathrm{X}$ flare events after a long absence of flares, and subduction zones under high tides. These two exceptional quakes indicate that X-flares together with other external conditions apparently could trigger conditions for unusually large quakes to occur.

\subsection{Flares Events, Worldwide Distribution of Earthquakes}

The last part of our study tries to track any connection between worldwide earthquakes distribution and X-flares. However, as we noticed in the two earthquakes analyzed in the previous section, it seems there is more than one condition necessary to create these occurrences. In this part of the study, we took all year events for each depth level and calculated which levels were more active. Therefore, we could find the disturbances for each level across twenty years.

The biggest enhancements in this area in the case of flares $\mathrm{X}>1$ happened most often at the level of $70-600 \mathrm{~km}$. Compared to the upper crust they vary at this depth in almost all years of maximum flares. Years without $X$ flares had less internal variation and showed a higher increase in activity in the crust 0 $70 \mathrm{~km}$. The east Pacific area shows that internal force disturbances are indeed more important than those at the earth's crust. The deepest depth, $600-800 \mathrm{~km}$, also showed disturbances linked to years of a maximum number of $\mathrm{X}$ flares as indicated in Figure 1. The Pacific area in Table 9 shows unique developments, and there are so many deep events as to indicate that the entire region is moving to close in some locations and open in others. Events below $800 \mathrm{~km}$ would not be possible in a region that is completely elastic or unbreakable; this activity points to variations in the stratigraphy that we do not yet know about. Longitudinal earthquake swarms in South America indicate a possible fault structure intraplate. Therefore, this research found two different aspects associated with earthquake enhancements. One is the internal variation in the enhancement of quakes above M4.5 that happened below the crust and the asthenosphere. The other one is atenuous link between tremors and extreme Solar events, probably associated with gravitational forces as well.

This region presented the biggest enhancement below $70 \mathrm{~km}$, as seen in Table 10. An increase in earthquakes in deeper regions are observed most in 2011 after five years without flares. In 2008, we see $\mathrm{X}=$ 0 showing an anomaly at depths of $35-70 \mathrm{~km}$. Finally, for $\mathrm{X}<1$ there was a substantial increase only in 2000 and 2014, the years of solar maximum. An anomaly occurred for shallower events at $0-35 \mathrm{~km}$ in 2016. The entire continent of Africa presented very few earthquakes below $40 \mathrm{~km}$ in depth. The deepest earthquake depth observed was in Malawi in 1998 with intensity M4.8 at $46.4 \mathrm{~km}$. It is possible that Africa does not have major fractures or faults, except in a small region of Tanzania. The other two regions, Asia and Europe, have anintense activity of earthquakes. When there is a higher number of X flares, the variation increases at depths below $70 \mathrm{~km}$. For years without flares, it does not happen. From 2000-2008, there is a gradual enhancement of events at depths of $35-70 \mathrm{~km}$. A small number of X-flares indicate a similar pattern to those observed with a high number of flares.

In this region (Table 11), earthquakes of intensity 4.5 or above are extremely rare in the depth 300 $500 \mathrm{~km}$. Such events only occurred four times over the last twenty years. This suggests diverse geological formation in these depths compared to the others analyzed so far. Below $500 \mathrm{~km}$ there are records of events again, mostly after the Andes cordillera that follows a nearly straight line from Brazil to the middle of Argentina. In this location, responses to higher X flares occur in the depth $200-300 \mathrm{~km}$ after 2000 . In 2015 , at $600-700 \mathrm{~km}$ the number of earthquakes reached three times the expected level. On the other hand, for years with no X flares, the most active year was 2009 at a depth of $600-700 \mathrm{~km}$. The Atlantic Ocean does not have any recorded event at depths lower than $250 \mathrm{~km}$ at the North Mid Atlantic Ridge in 
Table 9. Observe the variation of average earthquakes and $X$-flares with intensity $X>1$ (yellow) and $\mathrm{X}<1$ (blue) in the eastern Pacific area. Years without color included no record of $\mathrm{X}$ flares $(\mathrm{X}=0)$.

\section{East Pacific Ocean}

\begin{tabular}{|c|c|c|c|c|c|c|c|c|c|}
\hline Year & $\begin{array}{c}0-35 \\
\mathrm{~km}\end{array}$ & $\begin{array}{c}35-70 \\
\mathrm{~km}\end{array}$ & $\begin{array}{c}70-100 \\
\mathrm{~km}\end{array}$ & $\begin{array}{c}100-200 \\
\mathrm{~km}\end{array}$ & $\begin{array}{c}200-300 \\
\mathrm{~km}\end{array}$ & $\begin{array}{c}300-400 \\
\mathrm{~km}\end{array}$ & $\begin{array}{c}400-500 \\
\mathrm{~km}\end{array}$ & $\begin{array}{c}500-600 \\
\mathrm{~km}\end{array}$ & $\begin{array}{c}600-800 \\
\mathrm{~km}\end{array}$ \\
\hline 1996 & 1 & 0.3 & 0.9 & 0.9 & 0.9 & 1.1 & 1.3 & 1.3 & 0.7 \\
\hline 1997 & 0.7 & 0.3 & 1 & 1.1 & 1.1 & 1.2 & 1.3 & 1.1 & 0.8 \\
\hline 1998 & 0.6 & 0.6 & 1 & 1 & 1.4 & 0.9 & 1.1 & 1 & 1 \\
\hline 1999 & 0.9 & 0.4 & 1.1 & 1.1 & 1.1 & 0.9 & 1 & 0.9 & 1.4 \\
\hline 2000 & 1.1 & 0.5 & 0.9 & 1 & 1 & 0.9 & 0.9 & 0.8 & 1.6 \\
\hline 2001 & 1.1 & 0.6 & 1.1 & 1 & 1.1 & 1.1 & 1 & 1 & 0.7 \\
\hline 2002 & 0.7 & 0.5 & 0.9 & 0.9 & 1 & 1.1 & 1.2 & 1.2 & 1.7 \\
\hline 2003 & 0.8 & 0.5 & 1.1 & 0.9 & 0.9 & 1.4 & 1.1 & 1 & 0.5 \\
\hline 2004 & 0.7 & 0.3 & 1.1 & 1.1 & 0.9 & 0.7 & 1 & 1 & 1.6 \\
\hline 2005 & 0.6 & 1.1 & 1.1 & 1 & 1 & 1 & 1 & 1.1 & 0.6 \\
\hline 2006 & 1.6 & 2.1 & 2.1 & 2 & 2 & 2 & 2 & 2.1 & 1.6 \\
\hline 2007 & 1 & 1.1 & 0.9 & 1 & 0.9 & 0.9 & 1.1 & 0.9 & 0.9 \\
\hline 2008 & 0.8 & 1.2 & 0.9 & 0.9 & 0.9 & 1.5 & 0.9 & 0.9 & 0.9 \\
\hline 2009 & 1.1 & 1.2 & 1 & 0.9 & 0.8 & 0.9 & 0.7 & 0.5 & 1 \\
\hline 2010 & 1.3 & 1.5 & 0.8 & 0.9 & 0.9 & 0.8 & 0.6 & 0.7 & 1.1 \\
\hline 2011 & 1.3 & 1.8 & 1.2 & 0.9 & 1.1 & 0.9 & 0.8 & 0.6 & 0.8 \\
\hline 2012 & 0.8 & 1.3 & 1.3 & 1.1 & 1.1 & 1 & 0.9 & 0.8 & 0.7 \\
\hline 2013 & 0.9 & 1.1 & 1.2 & 1.1 & 1.1 & 1 & 0.9 & 1.1 & 1 \\
\hline 2014 & 0.7 & 1.2 & 0.9 & 1 & 0.9 & 0.8 & 1.1 & 1.2 & 1.2 \\
\hline 2015 & 0.9 & 1.3 & 1.1 & 1.2 & 1.2 & 1 & 0.9 & 1.3 & 1 \\
\hline 2016 & 1.9 & 0.1 & 1 & 1 & 0.9 & 0.9 & 0.8 & 1.3 & 0.8 \\
\hline
\end{tabular}

2005. Regions including the Pacific, Asia, Europe, and the Pacific side of South America presented internal enhancement and disturbance in the average number of earthquakes. The same happened in the East Southern Pacific where the earthquakes reached $600 \mathrm{~km}$. Another result is that the high X-flare disturbances may appear around the asthenosphere and below. Similar results happened in South America, Asia, and Europe. Those three places are the only ones that have earthquakes at the depths below $500 \mathrm{~km}$. This points to a possible well-localized anisotropy. This location showing several discrepancies and our next study will be on the issues observed here. However, they do not seem to be attached to external factors.

The next regions have fewer depths to consider: they are Canada, North America, and North Atlantic (Table A1); Arctic Sea and Greenland (Table A2); America, South Pacific, South Indian Ocean, and 
Table 10. Asia (West pacific), Europe, Africa. The years in green indicate flares $\mathrm{X}>1$, years in pink recordedflares $\mathrm{X}<1$. In uncolored years no event occurred.

\begin{tabular}{|c|c|c|c|c|c|c|c|c|c|}
\hline $\begin{array}{c}\text { West Pacific } \\
\text { (Asia) }\end{array}$ & Europe & Africa & & & & & & & \\
\hline Year & $0-35 \mathrm{~km}$ & $\begin{array}{c}35-70 \\
\mathrm{~km}\end{array}$ & $\begin{array}{c}70-100 \\
\mathrm{~km}\end{array}$ & $\begin{array}{c}100-200 \\
\mathrm{~km}\end{array}$ & $\begin{array}{c}200-300 \\
\mathrm{~km}\end{array}$ & $\begin{array}{c}300-400 \\
\mathrm{~km}\end{array}$ & $\begin{array}{c}400-500 \\
\mathrm{~km}\end{array}$ & $\begin{array}{c}500-600 \\
\mathrm{~km}\end{array}$ & $>600 \mathrm{~km}$ \\
\hline 1996 & 0.9 & 0.3 & 0.8 & 0.9 & 1 & 1.5 & 1.3 & 1.4 & 2 \\
\hline 1997 & 0.6 & 0.3 & 1 & 1.1 & 1.3 & 1 & 1.5 & 1.4 & 1.3 \\
\hline 1998 & 0.5 & 0.3 & 1 & 0.9 & 1 & 0.8 & 1.4 & 1 & 0.9 \\
\hline 1999 & 0.7 & 0.4 & 0.8 & 0.9 & 0.9 & 0.7 & 0.7 & 0.7 & 0.7 \\
\hline 2000 & 0.8 & 0.4 & 0.9 & 0.8 & 0.8 & 0.5 & 0.7 & 0.6 & 1.1 \\
\hline 2001 & 0.8 & 0.3 & 0.7 & 0.7 & 0.8 & 0.8 & 0.6 & 0.8 & 0.7 \\
\hline 2002 & 0.8 & 0.4 & 0.7 & 0.8 & 0.9 & 1 & 1.4 & 1 & 0.7 \\
\hline 2003 & 0.8 & 0.3 & 0.9 & 1 & 0.8 & 1.5 & 1.1 & 1.1 & 2 \\
\hline 2004 & 1 & 1.2 & 1.4 & 1.1 & 1.2 & 0.6 & 1 & 1.4 & 0.6 \\
\hline 2005 & 1.7 & 1.4 & 0.8 & 0.9 & 1 & 1.3 & 1.1 & 1 & 0.7 \\
\hline 2006 & 1.1 & 1.6 & 0.8 & 1 & 1 & 1.7 & 1.3 & 1.5 & 0.7 \\
\hline 2007 & 1.2 & 2 & 1.2 & 1.2 & 1.5 & 0.7 & 1 & 0.7 & 0 \\
\hline 2008 & 1.2 & 2.5 & 1.2 & 1.3 & 1.3 & 1.8 & 1.4 & 1.3 & 0.4 \\
\hline 2009 & 1.2 & 1.7 & 1.1 & 0.9 & 0.5 & 0.9 & 0.7 & 1 & 1.3 \\
\hline 2010 & 0.2 & 1.3 & 1 & 1.2 & 0.8 & 1 & 0.6 & 1.5 & 3.6 \\
\hline 2011 & 0.7 & 1.2 & 1.3 & 1.1 & 1.2 & 1.3 & 1 & 0.9 & 1 \\
\hline 2012 & 1 & 1.5 & 1.2 & 1.2 & 0.8 & 0.9 & 1.3 & 0.5 & 1 \\
\hline 2013 & 0.7 & 1.1 & 1 & 1 & 1.4 & 1.1 & 0.9 & 0.9 & 0.4 \\
\hline 2014 & 0.9 & 1.6 & 1.3 & 1 & 1.1 & 0.8 & 0.7 & 0.9 & 0.3 \\
\hline 2015 & 0.7 & 1.1 & 0.8 & 1 & 1.3 & 1.3 & 0.7 & 0.9 & 0.4 \\
\hline 2016 & 3 & 0.4 & 1 & 9 & 1 & 0.9 & 0.6 & 0.8 & 0.3 \\
\hline
\end{tabular}

Southern Ocean (Table A3). Canada, North America, Mexico and Central America dynamics are concentrated at shallow levels. No events occurred below $300 \mathrm{~km}$. However an anomaly increased a few of the deepest events in 1997 at $200-300 \mathrm{~km}$. In the regions of the Arctic Sea, Greenland and North Atlantic, events were also shallow. The other locations considered were Europe, North Africa, North Atlantic and the Caribbean. There was a strong enhancement of events at shallow depths. Moreover, the only location with earthquakes $300-500 \mathrm{~km}$ had a strong increase of events in eleven of twenty years. The variations of other regions according to the $\mathrm{X}$ flares are in Appendix, Tables A1-A3.

\section{RESULTS DISCUSSION}

Our first results showed that the growth of earthquakes is not periodic, nor does it follow the growth 
Table 11. In this region there are no occurrences in the interval $300-500 \mathrm{~km}$. The near-absence of events, with rare records after 2008, indicates a different kind of material at this depth or a variance in internal structure in this location. South Atlantic Ocean, South America.

\begin{tabular}{|c|c|c|c|c|c|c|c|}
\hline \multicolumn{8}{|c|}{ South Atlantic Ocean, South America } \\
\hline & $\begin{array}{c}0-35 \\
\mathrm{~km}\end{array}$ & $\begin{array}{c}35-70 \\
\mathrm{~km}\end{array}$ & $\begin{array}{c}70-100 \\
\mathrm{~km}\end{array}$ & $\begin{array}{c}100-200 \\
\mathrm{~km}\end{array}$ & $\begin{array}{c}200-300 \\
\mathrm{~km}\end{array}$ & $\begin{array}{c}500-600 \\
\mathrm{~km}\end{array}$ & $\begin{array}{c}600-700 \\
\mathrm{~km}\end{array}$ \\
\hline 1996 & 1 & 1.1 & 1.8 & 1.1 & 1.5 & 0 & 0 \\
\hline 1997 & 0.5 & 0.6 & 0.9 & 0.9 & 1.3 & 0.5 & 2 \\
\hline 1998 & 0.4 & 1.7 & 1 & 0.9 & 1.1 & 1.1 & 0.6 \\
\hline 1999 & 0.8 & 1.8 & 1 & 1 & 1.1 & 1 & 0 \\
\hline 2000 & 0.7 & 1 & 0.3 & 0.9 & 1.6 & 0.4 & 2.1 \\
\hline 2001 & 1 & 2.2 & 1 & 1.2 & 2 & 0 & 0 \\
\hline 2002 & 0.6 & 1.7 & 0.8 & 0.8 & 1 & 0.9 & 1 \\
\hline 2003 & 0.6 & 2 & 0.6 & 0.6 & 0.5 & 1.5 & 0.5 \\
\hline 2004 & 1 & 1.7 & 1.3 & 0.9 & 0.8 & 1.1 & 0 \\
\hline 2005 & 0.7 & 1.2 & 0.9 & 1 & 0.9 & 1.5 & 1.4 \\
\hline 2006 & 0.9 & 2 & 1 & 1.1 & 1.2 & 0.8 & 0 \\
\hline 2007 & 1 & 1.8 & 0.5 & 1.3 & 1.2 & 0.9 & 0.5 \\
\hline 2008 & 1 & 1.1 & 1.5 & 1.1 & 1.4 & 1.1 & 0 \\
\hline 2009 & 1 & 0.3 & 1 & 1 & 1.2 & 0.6 & 2.2 \\
\hline 2010 & 0.9 & 0.9 & 0.9 & 1 & 1 & 1.3 & 1 \\
\hline 2011 & 0.8 & 0.4 & 1.6 & 1.2 & 0.7 & 2.5 & 0 \\
\hline 2012 & 1 & 0.4 & 1.5 & 1.1 & 1.3 & 1.5 & 0.5 \\
\hline 2013 & 1.9 & 0.4 & 1.4 & 1.3 & 0.9 & 0.8 & 0.5 \\
\hline 2014 & 2 & 0.4 & 1.1 & 0.7 & 0.9 & 0.7 & 0.7 \\
\hline 2015 & 1.1 & 0.6 & 0.2 & 0.8 & 0.7 & 0.5 & 3 \\
\hline 2016 & 1.8 & 0.4 & 1.2 & 0.9 & 1.1 & 1.3 & 0.4 \\
\hline
\end{tabular}

of sunspots during the twelve years of the solar cycle as previously studied. What has been observed was quasi-periodic increases in the tremors at deeper layers, developing independently of any external events [1-3].

Such a result would be linked to an internal structure in some areas that is currently unknown. In fact, the terrestrial mantle could not be a homogeneous or partially melted structure as believed now. Instead, there would be points with a fragile structure that are easily broken and act according to internal variations by factors unidentified at present. These results were even more interesting in areas such as in the interior of the South American plate where there were no earthquakes between $300 \mathrm{~km}$ and $500 \mathrm{~km}$, 
but tremors reappeared below $500 \mathrm{~km}$ during the period studied. This thickness of $200 \mathrm{~km}$ without quakes indicates a highly stable structure, not brittle but malleable, which up to now has not been explained by any theory or experiment. On the other hand, the presence of earthquakes below $500 \mathrm{~km}$ shows a brittle thickness in this locality that can reach below $600 \mathrm{~km}$ or lower [18].

In this study, we found two different results. One was an indefinite discrepancy in depth, that indicates the average number of earthquake occurrences in twenty years is unlikely to relate to external disturbances. Nevertheless, some locations seemed to be affected by X flares occurrences. Here, we also described two earthquakes with magnitude above 8.0 that looked to be related to X-flares manifestations, and were also not associated with major quakes during a period without Xflares. Unfortunately, we do not have records of X-flares until 1996, when they started to be included in a public catalog.

Finally, we found an intriguing internal disparity focused at the locations with deepest earthquakes. Here it is possible that highly anisotropic regions $[19,20]$ in the entire areas observed could be the cause of those anomalies. Also, some electromagnetic disturbances to the entire magnetic field around the world might answer those questions Overall, it indicates that the mantle is not homogeneous and is distributed unequally worldwide.

\section{CONCLUSIONS}

We found an internal disturbance below the crust that varies randomly with depth. Three regions have a more severe discrepancy and earthquakes occurring at greater depths below the crust. There were severe incongruities that arose in the South Pacific on the west side. There is an anomalous dissimilarity located in South America (east side of Pacific): there is apparently an inactive level of $300-500 \mathrm{~km}$, but below this layer the activity returns. This shows that there is a sheet with a thickness of $200 \mathrm{~km}$ which is unknown by scientists. We will continue to search for an explanation for this part of the planet that acts in a unique way.

The possible relationship between coronal Mass ejections and solar flares from the Sun and their increase of electromagnetic activity and seismic events on earth can only be evaluated after another approach. The results pointed out internal forces that influence surges in earthquakes at a higher rate than external forces do. Isolating external forces will require specific study that transcends the scope of the current research.

\section{ACKNOWLEDGEMENTS}

Thanks to Paul Killinger to editing and correcting the English on this paper.

\section{REFERENCES}

1. Tavares, M. and Azevedo, A. (2011) Influences of Solar Cycles on Earthquakes. Natural Science, 3, 436-443. https://doi.org/10.4236/ns.2011.36060

2. Hagen, M. and Azevedo, A. (2016) Gravitational Moon-Earth Forces Triggering Earthquakes in Subduction Zones. Journal of Geography, Environment, and Earth Science International, 8, 1-14. https://doi.org/10.9734/JGEESI/2016/29227

3. Hagen, M. and Azevedo, A. (2017) Sun-Moon-Earth Interactions, External Factors for Earthquakes. Natural Science, 9, 162-180.

4. Meyer-Vernet, N. (2007) Basics of the Solar Wind. Cambridge University Press, Cambridge. https://doi.org/10.1017/CBO9780511535765

5. Russell, C.T. (2000) The Solar Wind Interaction with the Earth's Magnetosphere: A Tutorial. IEEE Transactions on Plasma Science, 28, 1818-1830.

6. Straser, V. and Cataldi, G. (2015) Solar Wind Ionic Variation Associated with Earthquakes Greater than Mag- 
nitude 6.0. New Concepts in Global Tectonics Journal, 3, 140-153.

7. Sibeck, D.G. (1990) A Model for the Transient Magnetosphere Response to Sudden Solar Wind Dynamic. Journal of Geophysical Research, 95, 3755-3771. https://doi.org/10.1029/JA095iA04p03755

8. http://www.spaceweatherlive.com/solar-activity/top-50-solar-flares/year/2000

9. Pressure Variations. http://services.swpc.noaa.gov/images/solar-cycle-sunspot-number.gif

10. http://cse.ssl.berkeley.edu/coronalweather/CMEsFlares/page3.html

11. http://solarscience.msfc.nasa.gov/greenwch.shtml

12. http://www.swpc.noaa.gov/phenomena/solar-flares-radio-blackouts

13. https://www.spaceweatherlive.com/en/solar-activity/top-50-solar-flares

14. http://www.swpc.noaa.gov/products/solar-cycle-progression

15. NGDC/NOAA. http://www.ngdc.noaa.gov/hazard/

16. USGS. https://earthquake.usgs.gov/earthquakes/search/

17. IRIS. http://ds.iris.edu/wilber3/find_event

18. Hagen, M. (2015) Mechanism of Intraplate Earthquakes and Anthropogenic Causes in the USA. Natural Science, 7, 459-474. https://doi.org/10.4236/ns.2015.79047

19. Crampin, S. and Chastin, S. (2003) A Review of Shear Wave Splitting in The Crack-Critical Crust. Geophysical Journal International, 155, 221-240. https://doi.org/10.1046/j.1365-246X.2003.02037.x

20. Stark, P.B. and Frohlich, C. (1985) The Depths of The Deepest Deep Earthquakes. Journal of Geophysical Research, 90, 1859-1869. https://doi.org/10.1029/JB090iB02p01859 


\section{APPENDIX}

Table A1. Canada, North America, Mexico, Central America. In this region there was an anomaly enhancement in 2011, all depths had increased ( $X>1$, green). The same occurred in 2008 ( $X=0$, no color). During the two-solar maximum we seean enhancement of events at depths of $35-200 \mathrm{~km}$.

\begin{tabular}{|c|c|c|c|c|c|}
\hline \multirow[b]{2}{*}{ Year } & \multicolumn{5}{|c|}{ Canada, North America, Mexico, Central America } \\
\hline & $0-35 \mathrm{~km}$ & $35-70 \mathrm{~km}$ & $70-100 \mathrm{~km}$ & $100-200 \mathrm{~km}$ & $200-300 \mathrm{~km}$ \\
\hline 1996 & 1.5 & 0.7 & 1.3 & 0.8 & 0.5 \\
\hline 1997 & 0.8 & 0.4 & 0.9 & 0.9 & 2.1 \\
\hline 1998 & 1 & 1 & 1 & 1 & 0.4 \\
\hline 1999 & 1 & 0.9 & 0.7 & 0.7 & 1.9 \\
\hline 2000 & 1.1 & 1 & 1.1 & 1.1 & 0.5 \\
\hline 2001 & 1.3 & 0.9 & 1.1 & 1.1 & 0.4 \\
\hline 2002 & 1 & 0.7 & 1 & 1 & 1 \\
\hline 2003 & 1.1 & 0.6 & 1.1 & 1.1 & 1.3 \\
\hline 2004 & 1.1 & 0.8 & 0.8 & 0.8 & 1.3 \\
\hline 2005 & 1 & 1 & 1.4 & 1.4 & 0.4 \\
\hline 2006 & 1 & 1.1 & 0.9 & 0.9 & 0.7 \\
\hline 2007 & 0.8 & 0.8 & 0.8 & 0.8 & 1.8 \\
\hline 2008 & 1 & 1.3 & 1 & 1 & 1 \\
\hline 2009 & 1.2 & 1 & 1.2 & 1.2 & 0.7 \\
\hline 2010 & 0.9 & 0.5 & 1 & 1 & 1.8 \\
\hline 2011 & 0.9 & 1 & 1.2 & 1.2 & 0.6 \\
\hline 2012 & 1 & 1.1 & 0.7 & 0.7 & 1.5 \\
\hline 2013 & 0.8 & 1.5 & 1 & 1 & 0.7 \\
\hline 2014 & 0.8 & 1.5 & 1 & 1 & 0.8 \\
\hline 2015 & 0.6 & 1.6 & 1.1 & 1.1 & 0.6 \\
\hline 2016 & 2.7 & 0.1 & 0.8 & 0.8 & 0.7 \\
\hline
\end{tabular}


Table A2. The region near the North Pole showed only shallow activity. $\mathrm{X}>1$ activity is indicated in blue, and $\mathrm{X}<$ 1 in yellow.

\begin{tabular}{|c|c|}
\hline \multicolumn{2}{|c|}{ Arctic Sea, Greenland, North Atlantic } \\
\hline Year & $0-35 \mathrm{~km}$ \\
\hline 1996 & 0.5 \\
\hline 1997 & 0.5 \\
\hline 1998 & 0.6 \\
\hline 1999 & 0.6 \\
\hline 2000 & 0.8 \\
\hline 2001 & 0.8 \\
\hline 2002 & 0.5 \\
\hline 2003 & 0.7 \\
\hline 2004 & 0.5 \\
\hline 2005 & 1.7 \\
\hline 2006 & 0.8 \\
\hline 2007 & 0.8 \\
\hline 2008 & 1.3 \\
\hline 2009 & 1.1 \\
\hline 2010 & 1 \\
\hline 2011 & 0.6 \\
\hline 2012 & 1.1 \\
\hline 2013 & 0.5 \\
\hline 2014 & 6 \\
\hline 2015 & 1.3 \\
\hline 2016 & 0.5 \\
\hline
\end{tabular}


Table A3. Locations near the South Pole and their earthquakes variations with $\mathrm{X}$ flares. $\mathrm{X}>1$ is shown in gray, $\mathrm{X}<1$ in orange. Events are occurring deeper than at the North Pole. However, deep quakes are rare.

S. Atlantic, S. Indian Ocean, S. Pacific, Southern Ocean

\begin{tabular}{|c|c|c|c|c|}
\hline Year & $0-35 \mathrm{~km}$ & $35-70 \mathrm{~km}$ & $70-300 \mathrm{~km}$ & $300-500 \mathrm{~km}$ \\
\hline 1996 & 2 & 0 & 2.5 & 0 \\
\hline 1997 & 2 & 0 & 1.7 & 0 \\
\hline 1998 & 1.7 & 0 & 1.7 & 0 \\
\hline 1999 & 1 & 0 & 1 & 2 \\
\hline 2000 & 3 & 0 & 0 & 0 \\
\hline 2001 & 3.5 & 0 & 0 & 0 \\
\hline 2002 & 2 & 0 & 2 & 0 \\
\hline 2003 & 2 & 0 & 2 & 0 \\
\hline 2004 & 0.9 & 0 & 1.6 & 1.3 \\
\hline 2005 & 1 & 0 & 1.4 & 1.4 \\
\hline 2006 & 1 & 1 & 1.9 & 0 \\
\hline 2007 & 1 & 1.3 & 1.6 & 0 \\
\hline 2008 & 1.3 & 1.5 & 1.1 & 0 \\
\hline 2009 & 1 & 1 & 0.9 & 1 \\
\hline 2010 & 0.9 & 2.4 & 0.3 & 0.3 \\
\hline 2011 & 0.9 & 1.2 & 1.8 & 0 \\
\hline 2012 & 1.1 & 1.1 & 1.9 & 0 \\
\hline 2013 & 1.4 & 1.3 & 1.4 & 0 \\
\hline 2014 & 1.5 & 1 & 1.5 & 0 \\
\hline 2015 & 0.9 & 0.8 & 0.9 & 1.3 \\
\hline 2016 & 1.2 & 0.6 & 0.9 & 1.3 \\
\hline
\end{tabular}

